\title{
APA RESPONS DAN HARAPAN SISWA SMA TENTANG BLENDED LEARNING?
}

\author{
I Made Kirna \\ Ida Bagus Nyoman Sudria \\ I Made Tegeh
}

Universitas Pendidikan Ganesha, Jln. Udayana No. 11 Singaraja

e-mail: mdkirna@gmail.com

\begin{abstract}
What are Responses and Expectations of Senior High School Students to Blended Learning? The effectiveness of learning innovation could not ignore an important aspect of student's characteristics. The purposes of this research were to (1) describe the response of high school (SMA) students towards learning chemistry delivered by blended learning (BL), and (2) to explore the expectations of students towards the online content and chemistry learning management deli-vered by BL. To obtain the responses and the expectations of students, 140 questionnaires distri-buted online to the grade nine of class XI MIA SMA students (respondents) in seven SMAin seven-regencies in Bali: SMAN 1 Gianyar, SMAN 1 Sidemen Karangasem, SMAN 2 Semarapura, SMAN 5 Denpasar, SMAN 1 Singaraja, SMAN 1 Kuta Utara, and SMAN 1 Kediri Tabanan. The result of the research shows that only 110 respondentscompleted a questionnaire of students responsesabout $\mathrm{BL}$ and 106 respondents completed questionnaires of students' expectations towards online content and management of BL. SMA students gave a positive response to the application of $\mathrm{BL}$ and provi-ded important inputs which were useful fordeveloping online content and management of BL for se-nior high school students.
\end{abstract}

Key Words: blended learning, chemistry instruction, online content

\begin{abstract}
Abstrak: Apa Respons dan Harapan Siswa SMA tentang Blended Learning? Efektivitas suatu inovasi pembelajaran tidak bisa mengabaikan aspek penting karakteristik siswa. Tujuan penelitian ini adalah untuk (1) mendeskripsikan respons siswa SMA terhadap pembelajaran kimia yang disampaikan secara blended learning (BL), dan (2) menjaring harapan siswa terhadap konten dan pengelolaan pembelajaran kimia yang disampaikan secara BL. Untuk memperoleh gambaran tentang respons dan harapan siswa tersebut, 140 angket disebarkan secara online ke siswa SMA kelas XI MIA yang tersebar di 7 SMA di 7 kabupaten/kodya di Bali, yaitu SMAN 1 Gianyar, SMAN 1 Sidemen Karangasem, SMAN 2 Semarapura, SMAN 5 Denpasar, SMAN 1 Singaraja, SMAN 1 Kuta Utara, dan SMAN 1 Kediri Tabanan. Hasil penelitian menunjukkan bahwa hanya 110 siswa yang mengisi angket respos siswa terhadap BL dan 106 responden yang mengisi angket harapan siswa terhadap konten online dan pengelolaan BL. Siswa SMA memberikan respon yang positif terhadap penerapan BL dan memberikan masukan yang berguna untuk mengembangkan konten online dan pengelolaan BL untuk siswa SMA.
\end{abstract}

Kata-kata Kunci: blended learning, konten online, pembelajaran kimia

Inovasi pembelajaran tidak bisa dilepaskan dari teknologi. Kemajuan information communication and technology (ICT) telah memudahkan pe- ngembang/praktisi pembelajaran untuk menyampaikan informasi dan bahkan mengelola aktivitas pembelajaran. Kemudahan ini telah menyema- 
rakkan pembelajaran online dan home schooling di Amerika (Watson, 2008). Pada awal kemunculannya, pembelajaran online menjanjikan mimpi besar tentang efektivitas dan bahkan efisiensi pembelajaran. Beberapa keunggulan yang dijanjikan pembelajaran online seperti memfasilitasi belajar kapan saja dan dimana saja, kekayaan format informasi yang bisa disampaikan, baik statis maupun dinamis, linear maupun nonlinear, serta memfasilitasi interaksi sosial menyebabkan optimisme yang tinggi akan kemampuannya dalam meningkatkan efektivitas pembelajaran.

Kemajuan ICT merupakan salah satu pilar pendukung dari paradigma baru pembelajaran yang menganut pandangan konstruktivisme. Salah satu inovasi pembelajaran sesuai dengan pandangan konstruktivisme yang direkomendasikan oleh kurikulum pendidikan nasional adalah pembelajaran menggunakan pendekatan inkuiri ilmiah atau saintifik. Pembelajaran menggunakan pendekatan ini mempersyaratkan siswa aktif, memiliki motivasi belajar, dan independensi belajar yang memadai. Sayangnya, sebagian siswa belum memiliki karakter tersebut. Aktivitas siswa (learning engagement) sering dikeluhkan oleh guru dalam mengelola pembelajaran. Sebagian besar siswa masih memiliki budaya belajar reseptif. Siswa datang ke kelas hanya siap untuk mendengarkan penjelasan guru. Keluhan guru ini sejalan dengan hasil observasi mahasiswa calon guru dalam mengelola pembelajaran di kelas. Suasana pembelajaran masih kering dengan pertanyaaan dan tanggapan siswa terhadap topik yang dibahas. Fenomena ini menyebabkan beberapa guru enggan melaksanakan pembelajaran menggunakan pendekatan ini.

Kurang aktifnya siswa dalam pembelajaran semestinya tidak mendorong guru kembali pada pandangan pembelajaran tradisional yang cenderung informatif. Hasil-hasil kajian psikologi pembelajaran dan neuroscience telah menemukan hakikat belajar yang mengarah kepada pandangan konstruktivisme. Hasil-hasil kajian tersebut disertai dengan keinginan untuk mengembangkan sumber daya manusia yang cerdas, berkarakter dan mampu bersaing menyebabkan inovasi pembelajaran tidak bisa diabaikan oleh praktisi pembelajaran. Budaya belajar reseptif siswa harus digeser ke budaya belajar aktif dan produktif serta menumbuhkan semangat belajar sepanjang hayat. Kemajuan ICT sekarang ini sangat poten-sial untuk mengembangkan lingkungan belajar konstruktivis untuk memfasilitasi pembelajaran menggunakan pendekatan saintifik. Pembelaja-ran berbasis ICT, yaitu online learning memiliki banyak keunggulan dilihat dari kekayaan sumber belajar (learning resources) dan aktvitas belajar (learning task).

Perjalanan pemanfaatan teknologi ICT dalam pembelajaran tidak serta merta membuktikan keunggulan yang dijanjikannya. Secanggih apapun teknologi, teknologi bukannya obat mujarab (panacea) yang bisa menyembuhkan semua penyakit, ataupun tongkat ajaib (magic wand) yang bisa dengan mudah menyelesaikan masalah. Teknologi tidak dengan sendirinya (stand alone) memberikan efektivitasnya dalam pembelajaran. Efektivitas teknologi sangat tergantung pada bagaimana teknologi tersebut diintegrasikan atau dimanfaatkan dalam pembelajaran (Roblyer, 2006). Modal kekayaan format informasi dalam suatu multimedia dan juga beragam fitur aktivitas belajar belum cukup untuk menjadikan ICT akan unggul dimanfaatkan dalam pembelajaran.

Pemanfaatan ICT dalam pembelajaran pada awalnya cenderung sebagai penyampai informasi yang sepenggal-sepenggal ataupun informasi yang strukturnya belum dikaji dengan cermat sesuai dengan kurikulum. Pemanfaatan ICT oleh praktisi pendidikan juga tanpa basis pedagogi memadai sehingga efektivitasnya sangat bervariasi. Beberapa temuan penelitian melaporkan bahwa pemanfaatan ICT memberikan hasil yang tidak konsisten (Passerini, 2007). Hasil yang tidak konsisten ini sebagian disebabkan oleh rendahnya kuatlitas sumber belajar berbasis ICT yang digunakan dan belum tepatnya strategi pengintegrasianya dalam pembelajaran. Leacock dan Nesbit (2007) menemukan bahwa sebagian besar kualitas lingkungan belajar online dan standar kualitas konten yang masih rendah dan belum dirancang sesuai dengan karakteristik subjek dan pedagogi. Pemanfaatan ICT masih mengalami banyak kendala, utamanya ketersediaan sumber belajar digital yang berkualitas dan literasi teknologi (internet) dari guru dan siswa (Hew \& Brush, 2007). Barger dan Byrd (2011) mengemukakan bahwa hal yang paling penting menentu- 
kan keberhasilan pembelajaaran online adalah ketersediaan lingkungan belajar online (konten online) yang tepat.

Keberhasilan pembelajaran online juga mempersyaratkan siswa yang self-directed, selfregulated, self diciplined, dan confortable with written communication memiliki karakter berbagi informasi, dan memiliki keterampilan teknis teknologi (Dabbagh \& Ritland, 2005). Independensi dan literasi teknologi maupun komunikasi adalah tiga hal yang sangat menentukan keberhasilan belajar online. Sebagian besar siswa belum memiliki karakteristik di atas, terutama independensi dalam belajar. Terkait dengan karakteristik siswa ini, Kirna (2013) menemukan bahwa penyebab kurang efektifnya pembelajaran online dikontribusi oleh budaya belajar siswa. Sebagian besar siswa belum terbiasa belajar aktif dan produktif. Gaya belajar siswa yang sudah terbentuk dari pembelajaran tradisional memerlukan waktu adaptasi yang cukup untuk menggeser gaya belajarnya yang cenderung pasif dengan gaya yang baru seperti ditawarkan oleh pembelajaran online. Artinya, strategi integrasi teknologi dalam pembelajaran tidak bisa mengabaikan karakteristik siswa. Morin, dkk. (2015) menyatakan bahwa "Perceptions are, therefore, important considerations when integrating technology into learning, especially virtual learning."

Temuan penelitian tentang kurang konsistennya efektivitas pembelajaran online memunculkan gagasan pendekatan ekliktik dengan memadukan keunggulan pembelajaran online dan tatap muka. Blended learning adalah kombinasi strategi penyampaian pembelajaran yang mengambil keunggulan pembelajaran online dan tatap muka. Temuan sejumlah penelitian (Vaughan, 2007; Kim \& Bateman, 2010; Shroff, \& Deneen, 2011; Rosenthal \& Weitz, 2012; Kirna, 2013) mengemukakan efektivitas dari penerapan BL. Hasil meta analisis dari sejumlah penelitian tentang BL telah menegaskan efektivitas pembelajaran berbantuan teknologi ini (Means, dkk., 2014). Dari meta analisis yang dilakukannya, Means, dkk. menemukan bahwa BL lebih efektif meningkatkan hasil belajar daripada pembelajaran online dan tatap muka yang dilakukan secara terpisah. Walaupun BL memberikan harapan besar untuk meningkatkan efektivitas pembelajaran, tetapi strategi penyampaian ini harus didu- kung oleh karakteristik siswa seperti sudah diuraikan di atas. Efektivitas BL sangat ditentukan oleh lingkungan belajar online yang dapat diadaptasikan dengan gaya belajar siswa dan secara gradual diharapkan mendorong kemandirian belajar siswa.

Berdasarkan paparan di atas, tujuan penelitian ini adalah untuk mengeksplorasi respons/ persepsi dan harapan siswa SMA terhadap pembelajaran kimia yang disampaikan secara BL. Persepsi dan harapan siswa ini sangat berguna dalam merancang konten online yang adaptif dan efektif untuk mendukung BL pada pembelajaran kimia SMA.

\section{METODE}

Penelitian ini termasuk penelitian desktiptif kualitatif untuk mendeskripsikan sekaligus menginterpretasi dan mengelaborasi temuan. Penelitian dilaksanakan pada tahun 2015. Responden penelitian adalah siswa SMA kelas XI MIA di 7 SMA yang tersebar di 7 kabupaten/kodya di Bali, yaitu SMAN 1 Singaraja, SMAN 1 Sidemen, SMAN 2 Semarapura, SMAN 1 Gianyar, SMAN 1 Kuta Utara, SMAN 5 Denpasar, dan SMAN 1 Kediri Tabanan. Pemilihan sekolah sebagai subjek penelitian didasarkan atas pertimbangan bahwa guru-guru Kimia di sekolah tersebut memiliki literasi yang baik dalam bidang ICT/internet sehingga pernah melaksanakan pembelajaran berbantuan teknologi internet.

Dua jenis angket dibuat pada penelitian ini, yaitu angket respons/persepsi siswa tentang pembelajaran kimia yang dilaksanakan secara BL dan angket harapan siswa tentang konten dan pengelolaan BL pada pembelajaran kimia di SMA. Angket respon siswa disusun mengacu pada teori motivasi Keller yang terdiri atas 3 dari 4 aspek yang dikemukakan Keller, yaitu atensi, kepercayaan diri (confidence), dan relevansi (Keller, 2000), dan satu aspek terkait dengan literasi responden terhadap ICT. Angket harapan siswa memuat empat aspek, yaitu karakteristik indikator pembelajaran, karakteristik materi dalam konten online, karakteristik tugas/aktivitas belajar online, dan pengelolaan BL.

Angket disebarkan secara online dimana setiap responden diberikan username dan password. Setiap responden hanya diijinkan men- 
submit isian angketnya sekali saja. Pengisian angket dikoordinasikan oleh salah satu guru kimia dari sekolah yang dijadikan subjek penelitian. Data respon siswa dianalisis menggunakan mean ideal (Mi) dan standar deviasi ideal (Si) untuk mengetahui level respon siswa terhadap BL. Hasil elaborasi respon siswa dan harapan siswa terhadap konten online dan pengelolaan BL dijadikan pertimbangan untuk merancang konten online dan strategi pengelolaan pembelajaran kimia SMA menggunakan pendekatan saintifik yang disampaikan secara BL.

\section{HASIL DAN PEMBAHASAN}

\section{Hasil}

Dari 140 responden yang disasar, hanya 110 responden $(78,6 \%)$ yang mengisi angket ten- tang respons siswa terhadap BL dan 106 responden $(75,7 \%)$ yang mengisi angket harapan siswa terhadap konten online dan pengelolaan BL. Dengan menggunakan $\mathrm{Mi}$ dan $\mathrm{Si}$ diperoleh acuan kategorisasi level respons siswa seperti dicantumkan dalam Tabel 1.

Respon siswa terhadap pembelajaran kimia yang disampaikan secara BL memokuskan pada empat aspek. Tiga aspek didasarkan pada teori motivasi Keller (atensi, relevansi, dan confidence), dan satu aspek menyasar pada literasi siswa terhadap ICT. Rekapitulasi respon siswa terhadap pembelajaran yang disampaikan secara BL adalah seperti disajikan pada Tabel 2. Rekapitulasi harapan siswa terhadap konten online dan strategi pengelolaan BL disajikan padaTabel 3.

Tabel 1. Kategorisasi Level Respon Siswa

\begin{tabular}{ccc}
\hline Acuan & Rentang skor & Kategori \\
\hline $\mathrm{X} .=\mathrm{Mi}+1,5 \mathrm{Sdi}$ & $>440$ & Sangat tinggi (ST) \\
\hline $\mathrm{Mi}+0,5 \mathrm{Sdi}<\mathrm{X}<\mathrm{Mi}+1,5 \mathrm{Sdi}$ & $366,7-440$ & Ttinggi $(\mathrm{T})$ \\
\hline $\mathrm{Mi}-0,5 \mathrm{Sdi}<\mathrm{X}<\mathrm{Mi}+0,5 \mathrm{Sdi}$ & $293,3-366,7$ & Cukup $(\mathrm{C})$ \\
\hline $\mathrm{Mi}-1,5<\mathrm{X}<\mathrm{Mi}-0,5 \mathrm{Sdi}$ & $220-293,3$ & Kurang (K) \\
\hline $\mathrm{X}<\mathrm{Mi}-1,5 \mathrm{Sdi}$ & $<220$ & Sangat kurang (SK) \\
\hline
\end{tabular}

Tabel 2. Level Respon Siswa terhadap Pembelajaran yang Disampaikan secara BL

\begin{tabular}{|c|c|c|}
\hline ATENSI & Skor & Ket \\
\hline Pembelajaran kimia menggunakan strategi blended learning inovatif dan menyenangkan & 436 & $\mathrm{~T}$ \\
\hline Saya senang jika sebagian besar pembelajaran telah memanfaatkan ICT & 428 & $\mathrm{~T}$ \\
\hline $\begin{array}{l}\text { Saya sudah pernah mengikuti pembelajaran blended (kombinasi online dan tatap muka, } \\
\text { sepertitugas mencari informasi secara online, ataudiskusi dengan jejaring sosial: face } \\
\text { book, line, atau dengan blog, email, moodle, atau yang lain) dan saya menyenangi itu }\end{array}$ & 384 & $\mathrm{~T}$ \\
\hline $\begin{array}{l}\text { Terlepas cocok atau tidak cocok dengan saya, saya ingin mengikuti pembelajaran yang } \\
\text { mengkombinasikan online dan tatap muka }\end{array}$ & 416 & $\mathrm{~T}$ \\
\hline Rata-rata atensi & 416 & $\mathrm{~T}$ \\
\hline RELEVANSI & Skor & Ket \\
\hline Pembelajaran berbasis ICTrelevan dengan kehidupan sekarang dan yang akan datang & 448 & ST \\
\hline $\begin{array}{l}\text { Saya kira, pembelajaran di masa yang akan datang akan cenderung berbasis teknologi } \\
\text { informasi dan komunikasi (ICT) }\end{array}$ & 446 & ST \\
\hline $\begin{array}{l}\text { Sekarang sudah saatnya inovasi pembelajaran diarahkan pada pemanfaatan ICT karena } \\
\text { sarananya sudah ada dan potensinya yang tinggi untuk memudahkan belajar }\end{array}$ & 434 & $\mathrm{~T}$ \\
\hline Rata-rata skor relevansi & 442,7 & ST \\
\hline KEPERCAYAAN DIRI (CONFIDENCE) & Skor & Ket \\
\hline $\begin{array}{l}\text { Pembelajaran yang sebagian dilakukan secara online hanya akan membuat saya sibuk } \\
\text { dan tidak cukup berartimembantu saya belajar (-) }\end{array}$ & 340 & $\mathrm{C}$ \\
\hline
\end{tabular}




\begin{tabular}{|c|c|c|}
\hline $\begin{array}{l}\text { Saya kira diskusi secara online akan meningkatkan diskusi karena bisa dilakukan pada } \\
\text { waktu dan tempat berbeda dan efektif untuk meningkatkan hasil belajar }\end{array}$ & 392 & $\mathrm{~T}$ \\
\hline $\begin{array}{l}\text { Saya kira pembelajaran blended (kombinasi online dan tatap muka ) akan } \\
\text { membingungkan (-) }\end{array}$ & 296 & $\mathrm{C}$ \\
\hline $\begin{array}{l}\text { Saya kira pembelajaran yang mengombinasikan online dan tatap muka akan cocok } \\
\text { asalkan dirancang dengan baik. }\end{array}$ & 476 & ST \\
\hline \multirow[b]{2}{*}{ LITERASI TEHRADAP ICT/INTERNET } & 376 & $\mathrm{~T}$ \\
\hline & Skor & Ket \\
\hline $\begin{array}{l}\text { Saya sudah terbiasa menggunakan teknologi informasi ini dalam keseharian, seperti } \\
\text { menggunakan Hp, facebook, dan internet. }\end{array}$ & 494 & ST \\
\hline $\begin{array}{l}\text { Saya sudah terbiasa mencari informasi dari internet dan membaca materi pelajaran secara } \\
\text { online atau di komputer }\end{array}$ & 484 & ST \\
\hline Rata-rata literasi terhadap ICT/internet & 489 & ST \\
\hline
\end{tabular}

Tabel 3. Harapan Siswa SMA terhadap Karakteristik Konten Online dan Strategi BL.

\begin{tabular}{|c|c|c|c|}
\hline Indikator Pembelajaran dalam Konten online & $\begin{array}{l}\mathrm{S} \\
(\%)\end{array}$ & $\mathrm{TS}(\%)$ & $\mathbf{T T}(\%)$ \\
\hline $\begin{array}{l}\text { Konten online perlu menyajikan secara jelasindikator pembelajaran untuk } \\
\text { setiap topik }\end{array}$ & 90.6 & 1.9 & 7.5 \\
\hline Indikator pembelajaransebaiknya dirumuskan cukup detail & 88.7 & 9.4 & 1.9 \\
\hline Jenis Materi dalam Konten online & $\begin{array}{l} \\
(\%)\end{array}$ & $\mathrm{TS}(\%)$ & $\mathbf{T T}(\%)$ \\
\hline $\begin{array}{l}\text { Setiap topik diberikan rangkuman materi sesuai dengan indikator } \\
\text { pembelajaran, selain materi pokok yang lengkap, }\end{array}$ & 100.0 & 0.0 & 0.0 \\
\hline $\begin{array}{l}\text { Konten online sangat penting memberikan contoh-contoh pemecahan masalah } \\
\text { dan fasilitas berdiskusi karena pengetahuan kimia bersifat abstrak. }\end{array}$ & 96.2 & 1.9 & 1.9 \\
\hline $\begin{array}{l}\text { Konten online sebaiknya dengan jelas memuat kaitan indikator dengan materi } \\
\text { dan tugas }\end{array}$ & 90.6 & 3.8 & 3.8 \\
\hline Materi berupa video praktikum penting disediakandalam konten online & 98.1 & 1.9 & 0.0 \\
\hline $\begin{array}{l}\text { Materi yang mengandung visualisasi/animasi ataupun simulasi sangat } \\
\text { membantu saya dalam memahami materi kimia. }\end{array}$ & 96.2 & 1.9 & 1.9 \\
\hline Tugas /Kegiatan Siswa dalam Konten Online & $\begin{array}{l}\mathrm{S} \\
(\%)\end{array}$ & $\operatorname{TS}(\%)$ & TT(\%) \\
\hline $\begin{array}{l}\text { Setiap topik mengandung tugas dan fasilitas untuk uploadtugas yang relevan } \\
\text { dengan indicator pembelajaran. }\end{array}$ & 92.5 & 3.8 & 3.8 \\
\hline Tugas yang sama, sebaiknya bisa diuploadlebih dari satu kali. & 67.9 & 15.1 & 17.0 \\
\hline Setiap topik mengandung Forum untuk diskusi online & 92.5 & 3.8 & 3.8 \\
\hline Pengelolaan Blended Learning & $\begin{array}{l}\mathrm{S} \\
(\%)\end{array}$ & $\operatorname{TS}(\%)$ & $\mathbf{T T}(\%)$ \\
\hline $\begin{array}{l}\text { Setiap topik perlu dicantumkan jadwal kegiatan online dan tatap muka di } \\
\text { kelas. }\end{array}$ & 77.4 & 11.3 & 11.3 \\
\hline $\begin{array}{l}\text { Tidak semua indikator pembelajaran harus ada kegiatan online dan tatap } \\
\text { muka nya. Indikator tertentu cukup online saja. }\end{array}$ & 45.3 & 39.6 & 15.1 \\
\hline $\begin{array}{l}\text { Indikator pembelajarantertentu tidak perlu online, langsung tatap muka di } \\
\text { kelas saja }\end{array}$ & 43.4 & 37.7 & 17.0 \\
\hline $\begin{array}{l}\text { Untuk mencapaiindikator pembelajaran, sebaiknya dijelaskan dahulu } \\
\text { materinya secaratatap muka kemudian dilanjutkan dengan kegiatan online }\end{array}$ & 94.3 & 3.8 & 1.9 \\
\hline
\end{tabular}




\begin{tabular}{|c|c|c|c|}
\hline $\begin{array}{l}\text { Saya lebih senang pembelajaran disetiap topik dimulai dengan tugas online } \\
\text { dahulu, kemudian dibahaspada saat tatap muka. }\end{array}$ & 26.4 & 67.9 & 5.7 \\
\hline Belajar online lebih baik dirancang berkelompok daripada individual & 71.7 & 15.1 & 13.2 \\
\hline Diskusi kelompok secara online sebaiknya tertutup untuk kelompok yang lain. & 41.5 & 45.3 & 13.2 \\
\hline $\begin{array}{ll}\text { Keterangan : } & \mathrm{S}=\text { setuju } \\
& \mathrm{TS}=\text { tidak setuju } \\
& \mathrm{TT}=\text { tidak tentu/ragu-ragu }\end{array}$ & & & \\
\hline
\end{tabular}

\section{Pembahasan}

Atensi/ketertarikan siswa terhadap pembelajaran kimia yang disampaikan secara blended termasuk kategori tinggi. Walaupun sebagian responden belum pernah terlibat dalam pembelajaran BL atau mengikuti BL hanya sebatas tugas mencari informasi di internet, tetapi sebagian besar responden menyenangi aktivitas tersebut. Atensi yang tinggi reponden terhadap penerapan BL terlihat dari harapan mereka agar sebagian besar pembelajaran dilaksanakan dengan memanfaatkan ICT dan mereka ingin mengikuti pembelajaran BL terlepas dari strategi itu cocok atau tidak cocok dengan cara/kebiasaan belajarnya.

Ketertarikan yang tinggi terhadap penerapan BL merupakan titik awal yang positif terhadap penerapan BL. Marzano (1993) menyatakan bahwa sikap dan persepsi yang positif terhadap pembelajaran adalah fokus pertama dari lima dimensi belajar agar pembelajaran efektif. Tanpa sikap dan persepsi yang positif terhadap pembelajaran, siswa tidak akan melakukan usaha yang optimal dalam belajar. BL telah dipersepsi positif oleh siswa SMA dan persepsi ini perlu dipertahankan melalui perancangan yang baik.Keller (2000) menyatakan bahwa mempertahankan atensi adalah bagian terakhir yang mesti dilakukan pada aspek atensi dari model motivasi Attention, Relevance, Confidence, Satisfaction (ARCS) yang digagasnya.

Relevansi adalah aspek kedua dari model motivasi ARCS. Walaupun siswa memiliki rasa ingin tahu yang tinggi dan atensi yang sangat tinggi, tetapi motivasinya akan hilang apabila tidak memberikan nilai manfaat kepada dirinya. Sesuatu yang sesuai/relevan dengan kebutuhan atau tujuan akan meningkatkan motivasi (Keller, 2000). Tiga item pernyataan dikaitkan dengan relevansi penggunaan teknologi bagi siswa, yaitu pentingnya penguasaan teknologi ICT di kehidu- pan masa mendatang, kebutuhan belajar di masa depan, dan pentingnya penguasaan ICT untuk memudahkan belajar. Dari ketiga item tersebut, respons responden termasuk sangat tinggi. Respon yang sangat tinggi mengindikasikan bahwa pembelajaran BL potensial meningkatkan partisipasi siswa dalam pembelajaran.Terkait dengan relevansi, sangat penting mengaitkan pengalaman belajar siswa dengan pengalaman menggunakan teknologi seperti yang diharapkan oleh siswa.

Kepercayaan diri untuk berhasil/sukses adalah aspek penting dari model motivasi ARCS. Ada empat item kuesioner yang diarahkan pada aspek kepercayaan diri. Dua item yang memuat pernyataan negatif mengindikasikan bahwa sebagian siswa pesimis bisa meningkatkan hasil belajar kimia, walaupun mereka akan lebih sibuk belajar. Disisi lain, pembelajaran dengan BL bisa jadi akan membingungkan mereka. Respons siswa ini bisa jadi berasal dari refleksi mereka terhadap pembelajaran berbantuan internet yang pernah diikuti. Pertama, pembelajaran berbantuan ICT sudah menjadi trend sekarang ini di Bali. Guru-guru, terutama di kota sudah sering memberikan tugas-tugas terkait dengan sumber belajar yang ada di internet, baik langsung maupun tidak langsung. Siswa, dalam menyelesaikan tugas-tugas belajarnya sudah banyak mengandalkan informasi yang ada di internet. Tetapi sayangnya, tugas-tugas yang sudah dikerjakan siswa kurang mendapatkan eleborasi/diskusi yang memadai pada pembelajaran tatapmuka. Dalam pembelajaran berbantuan internet yang dialami oleh siswa, sebagian besar memposisikan siswa sebagai "pemulung informasi" saja. Tugas-tugas belajar yang diberikan guru hanya selesai sampai siswa mengumpulkan informasi saja. Tentu saja, pembelajaran berbantuan internet ini kurang efektif, siswa cukup sibuk, tetapi kurang mengkontribusi pada peningkatan pemahaman. Di samping itu, sebagian informasi yang ada di in- 
ternet memiliki standar kualitas yang rendah dan ketinggalan jaman (inappropriate material) (Smaldino, dkk., 2005). Internet adalah "keranjang informasi." Sebagai suatu keranjang, pada internet berlaku Garbage In Garbage Out (GIGO). Pembelajaran yang membebaskan siswa mengakses informasi secara online sangat beresiko menimbulkan kebingungan dari informasiinformasi yang bervariasi tersebut.

Walaupun sebagian siswa menyatakan BL berpotensi membingungkan, tetapi diskusi online diyakini akan membantu mereka belajar. Keyakinan siswa sangat tinggi pada BL. Keyakinan ini akan membantu mereka belajar apabila BL dirancang dengan baik. Hal ini mengindikasikan bahwa pembelajaran berbantuan internet yang pernah mereka alami dirasakan tidak memuaskan, tetapi mereka masih mempunyai harapan yang tinggi bahwa BL akan efektif. Secara keseluruhan, respons siswa terhadap aspek confidence tergolong kategori tinggi, walaupun beberapa item respon menunjukkan sebagian siswa masih meragukan bahwa mereka akan berhasil dalam pembelajaran yang disampaikan secara BL. Pentingnya keyakinan diri dikaitkan dengan aktivitas siswa dalam mencapai keberhasilan belajar dinyatakan oleh Schunk, Pintrich, \& Meece (2008) bahwa "Students who feel selft-confident about learning and performing well in school seek challenges, expend effort to learn new material, and persist at difficult tasks."

Keseluruhan respons positif siswa terhadap tiga aspek motivasi dari model ARCS termasuk kategori tinggi. Siswa SMA di Bali yang menjadi responden memiliki motivasi awal yang tinggi terhadap pembelajaran kimia yang disampaikan secara BL. Respons positif sangat berkaitan dengan partisipasi aktif siswa dalam pembelajaran (Barger \& Byrd, 2011). Motivasi awal yang baik perlu dijaga dengan merancang pembelajaran $\mathrm{BL}$ yang berbasis pada model motivasi. Hasil metaanalisis yang dilakukan oleh Means, dkk. (2014) telah menegaskan bahwa keunggulan BL dari pembelajaran online dan tatap muka salah satunya disebabkan oleh time engagement (lamanya waktu siswa berinteraksi aktif dalam lingkungan belajar online). Time engagement ini dikontribusi oleh fleksibilitas pembelajaran online dari segi waktu dan tempat dan juga faktor motivasi. Dalam kaitan ini, perancangan BL sangat penting berlandaskan pada kebutuhan siswa dan Means, dkk., (2014) merekomendasikan riset pengembangan BL untuk berbagai karakteristik siswa.

Hasil kuesioner terhadap literasi ICT/internet memperlihatkan bahwa sebagian besar (ratarata skor 489 dari skor maksimum 550) atau hampir $100 \%$ siswa menyatakan setuju sampai sangat setuju bahwa mereka sudah biasa menggunakan internet dan mencari informasi diinternet. Ini menunjukkan bahwa seluruh siswa SMA yang bertindak sebagai responden memiliki literasi yang memadai menggunakan internet sehingga penerapan BL tidak mengalami kendala karena faktor keterampilan terkait teknologi ini. Dengan demikian, baik respon siswa terhadap BL dan keterampilan (skill) telah mendukung penerapan BL untuk siswa SMA di sekolah yang dijadikan responden di Bali. Hasil-hasil penelitian memperlihatkan bahwa respons positif dan skill adalah faktor kunci dalammemulai pembelajaran berbasis ICT (Alayar, Fisser, \& Voogt, 2012). Tentu, respon dan keterampilan menggunakan internet ini belum menjamin pembelajaran berbasis ICT, seperti BL, akan efektif. Beberapa hasil penelitian menemukan bahwa keberhasilan pembelajaran online mempersyaratkan siswa agar memiliki kemampuan self-directed learning, motivasi internal, internal locus of control, keterampilan berkolaborasi, dan karakter membagi informasi (Dabbagh \& Ritland, 2005).

Sebagaimana disarankan oleh Means, dkk. (2014), perancangan BL harus melihat kebutuhan dan harapan siswa. Analisis hasil kuesioner tentang harapan siswa terhadap konten online dan pengelolaan BL memberikan beberapa informasi tentang perancangan pembelajaran kimia yang disampaikan secara BL untuk siswa SMA di Bali. Pertama, siswa mengharapkan agar indikator pembelajaran di setiap topik dirumuskan secara detail dalam lingkungan belajar online (konten online). Indikator pembelajaran yang detail lebih memandu siswa secara jelas tentang apa yang harus dikuasainya dibandingkan dengan rumusan yang sifatnya masih umum.

Kedua, siswa juga mengharapkan bisa melihat dengan jelas kaitan antara indikator pada setiap topik dengan materi dan tugas. Bransford, Brown, dan Cocking (2000) menyatakan bahwa kejelasan kaitan antara tujuan dengan apayang dipelajari, bagaimana cara mempelajarinya, dan 
bagaimana mengevaluasinya sangat penting dalam lingkungan belajar. Tanpa kaitan tersebut, sulit mengetahui apa yang akan dipelajari. Kejelasan kaitan komponen pokok di atas sangat penting dipertimbangkan dalam mengembangkan lingkungan belajar online.

Ketiga, seluruh responden mengharapkan agar dalam konten online diberikan rangkuman materi untuk setiap indikator. Harapan siswa ini mengindikasikan bahwa siswa mengalami kesulitan dalam menemukan pengetahuan kunci yang mesti difokuskan dalam belajar dari sumber informasi yang kompleks, seperti paparan dalam buku ajar. Harapan siswa ini sejalan dengan yang dikemukakan oleh Talaris Research Institute (Allen's, 2007) bahwa pembelajar akankurang optimal belajar dari informasi yang banyak yang disampaikan secara linear. Tambahan informasi yang kurang tepat (menjelaskan banyak hal) akan mengganggu pemerolehan informasi yang penting dari materi yang dipelajari. Marzano (2006) juga melaporkan bahwa konten yang terlalu banyak tidak efektif meningkatkan hasil belajar. Penekanan pembelajaran pada konsepsi kunci dan elaborasi secukupnya cenderung lebih efektif.

Keempat, hampir seluruh responden (lebih dari 96\%) mengharapkan konten online untuk pembelajaran kimia penting diberikan, misalnya contoh pemecahan masalah dan visualisasi, baik video fakta maupun animasi/simulasi. Konsepsi kimia bersifat tidak kasat mata. Memahami kimia memerlukan kemampuan berimajinasi dan bernalar yang tinggi tentang materi dan perubahan materi yang hanya bisa dijelaskan dari sudut pandang submikroskopis yang tidak kasat mata. Siswa mengalami kesulitan memahami aspek submikroskopis ini dari penjelasan verbal sehingga kimia termasuk pelajaran yang dipandang sulit. Visualisasi berupa anilmasi/simulasi akan membantu siswa dalam mengkonkretkan konsepsi yang abstrak. Disamping itu, dilihat dari tingkat abstraksi pesan, informasi yang disampaikan secara visual lebih konkret daripada informasi verbal sehingga informasi yang disampaikan secara visual lebih mudah dipahami dari informasi verbal. Allen's (2007) menegaskan hal ini dengan menyatakan "Half of the human brain cortex is devoted to processing visual imformation. We process visual imformation more effect- tively than any other type."Anglin, Vaez, dan Cunningham(2004) menegaskannya sebagai picture superior effect. Sejumlah penelitian dalam pembelajaran kimia telah melaporkan keunggulan penggunaa visualisasi (Sanger, dkk., 2007; Treagust, dkk., 2010; Kirna,' 2012; Wijaya, Kirna, \& Suardana, 2012). Keunggulan visualisasi dalam pembelajaran kimia juga didukung oleh kemampuan visualisasi dalam meningkatkan motivasi belajar, terutama dilihat dari ketertarikan siswa (Falvo, 2008). Walaupun banyak keunggulannya, Falvo juga mengingatkan bahwa penerapan visualisasi dalam pembelajaran memerlukan diskusi/penegasan setelah siswa mencermati visualisasi karena banyak siswa memiliki pemahaman yang salah sebagai pengaruh dari pengetahuan awal. Desain dan strategi integrasi visualisasi dalam pembelajaran masih perlu dikaji.

Kelima, tugas berupa lembar kerja (task) adalah komponen yang mendorong aktivitas belajar siswa. Pembelajaran menggunakan pendekatan saintifik seperti direkomendasikan oleh kurikulum 2013 (K-13) identik dengan pembelajaran yang berbasis tugas (task-oriented). Siswa menjadi termotivasi melalui pemberian tugas yang akan mendorong siswa belajar secara aktif (Schunk, Pintrich, \& Meece, 2008). Merrill (2009) juga telah menegaskan bahwa pemberian tugas akan berimbas pada siswa belajar secara aktif yang merupakan salah satu prinsip penting dari pembelajaran. Terkait dengan tugas, responden mengharapkan agar setiap topik diberikan tugas-tugas sesuai dengan indikator. Walaupun tidak dominan, sebagian responden $(67,9 \%)$ mengharapkan agar mereka diberikan kesempatan untuk mengirim (upload) tugas lebih dari satu kali. Kelompok responden ini memandang perlu diberi kesempatan untuk melakukan revisi untuk menyempurnakan tugas belajarnya.

Kaitan yang jelas antara tugas dan indikator penting dieksplisitkan untuk memandu siswa mencapai indikator. Melalui tugas yang fokus pada pencapaian indikator, aktivitas belajar siswa menjadi lebih terarah. Konstruksi pengetahuan akan lebih bermakna apabila pengetahuan ditanam dalam aktivitas. Allen's (2007) menegaskan hal ini bahwa "meaning making is prompted by problem, question, confusion, disagreement, or dissonance." Oleh sebab itu, konten online pen- 
ting dibangun dengan "menjangkarkan" pengetahuan dalam aktivitas dimana permasalahan dipecahkan saat mengerjakan tugas. Materi penting disegmentasi dalam suatu potongan materi ( $m a-$ nageable chunk) dan siswa diberikan tugas latihan mengacu pada materi tersebut serta didorong untuk berinteraksi secara kolaboratif. Watson (2008) menyatakan bahwa tugas latihan sangat penting apabila (1) relevan dengan tujuan (indikator), (2), diberikan fleksibilitas dari segi waktu dan tempat dalam mengerjakannya, (3) mengandung jenis latihan dan permasalahan yang bervariasi, (4) menantang usaha yang cukup untuk berpikir, tidak hanya mengingat, dan (5) diberikan feedback yang sifatnya penjelasan (explanatory feedback).

Keenam, salah satu keunggulan pembelajaran berbasis ICT sekarang ini adalah tersedianya fasilitas untuk diskusi kolaboratif secara online. Kirna dan Mahadewi (2013) menemukan bahwa diantara sejumlah fitur konten online yang disediakan, forum diskusi online adalah yang paling intensif diakses mahasiswa tingkat 1 , baik untuk berpartisipasi aktif maupun hanya sebatas mereviu diskusi yang sudah dilakukan. Means, dkk. (2014) juga menemukan bahwa efektivitas pembelajaran BL salah satunya dikontribusi oleh interaksi siswa dengan siswa. Diskusi online memiliki keunggulan yaitu pembelajar memiliki kebebasan psikologis dalam mengajukan dan menanggapi permasalahan teman (Kirna, 2013). Temuan ini lebih dipertegas oleh Roberts dan Kanagasabai (2013) yang melaporkan bahwa pembelajar secara signifikan lebih menyukai posting problem atau tanggapan ke forum diskusi secara anonim (anonymous posting) disbandingkan dengan tidak anonim (identified posting). Terkait dengan diskusi online, responden mengharapkan agar setiap topik dilengkapi dengan forum diskusi online.

Ketujuh, respon responden terhadap beberapa item terkait dengan pengelolaan BL tidak ada yang dominan (kisaran 26, 4\% sampai $71,7 \%$ ), kecuali pada item harapan responden agar pembelajaran BL dimulai dari kegiatan tatap muka, kemudian dilanjutkan dengan online. Harapan responden ini mencerminkan bahwa siswa belum bisa lepas dari budaya belajar menerima (receptive learning) yang sudah ditradisikan dalam pembelajaran konvensional. Simpulan di atas didukung oleh sangat sedikitnya responden $(26,4 \%)$ yang menyenangi pembelajaran yang dimulai dari kegiatan online kemudian dilanjutkan dengan pembahasan pada kegiatan tatap muka. Secara gradual, budaya belajar menerima harus digeser ke paradigma belajar yang dianut sekarang ini, yaitu belajar sesuai dengan pandangan konstruktivisme yang dicirikan oleh (1) belajar adalah konstruksi pengetahuan sesuai dengan gaya belajar masing-masing, (2) belajar berbasis pengetahuan awal, (3) belajar berorientasi tugas-tugas bermakna, (4) belajar melalui pengalaman bereksplorasi, berhipotesis, memanipulasi objek, mengajukan pertanyaan, mencari jawaban, berargumentasi, dan menemukan, (5) belajar melalui interaksi sosial, dan (6) belajar melalui pengalaman mengaplikasikan pemahaman pada konteks yang baru.

Pembelajaran menurut pandangan konstruktisme ini menuntut penciptaan lingkungan belajar yang kaya dengan sumber informasi ( $m a-$ terial reources) dan elemen aktivitas. Kemajuan ICT sekarang ini sudah memudahkan pengembang pembelajaran menciptakan lingkungan belajar konstruktivis tersebut. Kemajuan ICT telah membuka peluang yang sangat besar menggeser tradisi belajar menerima (belajar dengar) menjadi belajar aktif dan produktif sesuai pandangan konstruktivisme. Penerapan BL harus tetap diarahkan untuk mentradisikan belajar sesuai dengan pandangan konstruktivisme, walaupun responden berharap sebaliknya.

Sebagian besar responden $(71,1 \%)$ mengharapkan pembelajaran dengan BL dilakukan secara berkelompok. Ini menunjukkan bahwa sebagian besar siswa sudah dapat mengambil manfaat dari belajar secara kolaboratif. Walaupun demikian, ternyata cukup banyak juga responden $(41,5 \%)$ menginginkan diskusi online secara kelompok yang tertutup bagi kelompok lain. Ini menunjukkan bahwa sebagian siswa masih memiliki jiwa kompetisi yang cukup tinggi antar siswa. Siswa dengan karakter kompetitif yang tinggi cenderung individual.

Kedelapan, walaupun tidak cukup dominan, sebagian responden $(54,7 \%)$ berpendapat bahwa semua indikator pembelajaran harus ada kegiatan online dan tatap mukanya. Kegiatan tatap muka masih menjadi keharusan untuk dilakukan. Bahkan, 43,4\% responden menegaskan 
bahwa indikator tertentu tidak perlu ada kegiatan online, langsung tatap muka saja. Sebagian besar responden memandang sangat penting dilakukan diskusi pada kegiatan tatap muka dimana guru memberikan penguatan dan konfirmasi. Siswa kurang memiliki kepercayaan diri tentang pemahaman yang dibangunnya dari kegiatan online. Strukturisasi guru masih sangat perlu dilakukan yang berkontribusi pada keteracapaian tujuan pembelajaran (Kischner, Sweller, \& Clark, 2010). Sesuai dengan harapan responden tersebut, pengelolaan BL untuk siswa SMA sekarang ini masih cenderung pada supplemented $\mathrm{BL}$, yaitu kegiatan online diarahkan sebagai suplemen kegiatan tatap muka, bukan menggantikan (replacement) kegiatan tatap muka

\section{DAFTAR RUJUKAN}

Anglin, G. J., Vaez, H. \& Cunningham, K. L. 2004. Visual Representations and Learning: The Role of Static and Animated Graphics. Dalam David H. Jonassen (Ed.). Handbook of Research on Educational Communications and Technology (hlm. 865-916). Mahwah: Lawrence Erlbaum Associates.

Allen's, M. 2007. Designing Successful ELearning: Forget What You Know About Instructional Design and Do Something Interesting. San Francisco: Pleiffer

Allayar, G. M., Fisser, P., Voogt, F. 2012. Developing Technological Pedagogical Content Knowledge jn Pre-Service Science Teachers: Support from Blended Learning. Australasian Journal of Educational Technology, 28(8): 1298-1316.

Barger, A., \& Byrd, K, 2011.Motivation and Computer-Based Instructional Design. Journal of Cross-Disciplinary Perspectives in Education, 4(1): 1-9.

Bransford, J. D., Brown, A. L., \& Cocking, R. C. 2000.How People Learn, Brain, Mind, Experience, and School. Washington. DC.: National Academy Press.

Dabbagh, N., \& Ritland, B. B. 2005. Online Learning: Concepts, Strategies, and Appli-

\section{SIMPULAN}

Siswa SMA memberikan respons yang positif terhadap pembelajaran kimia yang disampaikan secara Blended Learning (BL), baik dilihat dari atensi (ketertarikan), relevansi maupun konfidensi. Persepsi dan motivasi awal yang tinggi dari siswa SMA ini perlu dijaga dengan merealisasikan pembelajaran blended yang didesain dengan baik. Harapan siswa terhadap karakteristik lingkungan belajar online dan pengelolaan $\mathrm{BL}$ penting diperhatikan pengembang pembelajaran berbasis teknologi ICT untuk memperoleh suatu learning resources yang sesuai dengan kebutuhan belajar siswa SMA.

cation. Upper Saddle River: Pearson Education, Inc.

Falvo, D. 2008. Animations and Simulations for Teaching and Learning Molecular Chemistry. International Journal of Technology in Teaching and Learning, 4(1): 68-77.

Hew, K. F., \& Brush, T. 2007. Integrating technology into K-12 teaching and learning: Current knowledge gaps and recommenddations for future research.Educational Technology Research and Development, 55(3): 223-252.

Keller, J. M. 2010. What is Motivational Design? (Online), (www.springer. com/.../9781441 912497-c1.pdf?, diakses 20 Oktober 2015)

Kim, H. K. \& Bateman, B. 2010. Student Participation Patterns in Online Discussion: Incorporating Constructivist Discussion into Online Courses. International Journal on E-Learning, 9(1): 79-98.

Kirna, I. M. 2012. Pemahaman Konseptual Pebelajar Kimia Pemula dalam Pembelajaran Berbantuan Multimedia Interaktif. Jurnal Ilmu Pendidikan, 18(1): 88-97

Kirna, I M. 2013.Penerapan Strategi Problem Posing yang disampaikan secara Blended Learning pada Perkuliahan Chemical Bonding. Proseding Seminar Nasional FMIPA III di UNDIKSHA, 30 Nopember 2013. 
Leacock, T. L. \& Nesbit, J. C. 2007.A Framework for Evaluating the Quality of Multimedia Learning Resources.Educational Technology \& Society, 10 (2): 44-59

Marzano, R. J., Pickering, D., \& McTighe, J. 1993. Assessing Students Outcomes, Performance Assessment Using The Dimensions of Learning Model. Alexandria: ASCD.

Marzano. R. J. 2006. Classroom Assessment \& Grading That Work. Alexandria: ASCD.

Means, B., Toyama, Y., Murphy, R., \& Baki, M. (2014). The Effectiveness of Online and Blended Learning: A Meta-Analysis of the Emperical Literature. Teachers College Record, 115: 1-47.

Merrill, M. D. 2009. First Principles of Instruction. Dalam C. M. Reigeluth, \& A. A. Char-Cheliman (Eds.). Instructional-Design Theories and Models:Building a Common Knowledge Base, Vol.3 (hlm. 4156), New York: Routledge.

Morin, D., Thomas, J. D. E., \& Saadé, R. G. 2015.Fostering Problem-Solving in a Virtual Environment.Journal of Information Technology Education: Research, 14:339362.

Passerini, K. 2007. Performance and Behavioral Outcomes in Technology Supported Learning: The Role of Interactive Multimedia. Journal of Educational Multimedia and Hypermedia, 16(2): 183-210.

Roberts, L. D., \& Kanagasabai, C. J. R. 2013. I'd be so much more Comfortable Posting Anonymously: Identified versus Anonymous Participation in Student Discussion Boards. Australasian Journal of Educational Technology, 29(5): 612-625.

Roblyer, M. D. 2006.Integrating Educational Technology into Teaching. $\left(4^{\text {th }}\right.$ Ed.). Upper Saddle River: Pearson Merrill Prentice Hall.

Rosenthal, D. \& Weitz, R. 2012. Large-Course Redesign via Blended Learning: A PostImplementation Assessment Across Insti- tutions. International Journal on E-Learning, 11(2): 189-207

Sanger, M. J., Campbell, E., Felker, J. \& Spencer, C. 2007. Concept Learning ver-sus Problem Solving: Does Particle Mo-tion Have an Effect? J. Chem. Educ.,84: 875.

Schunk, D. H., Pintrich. P. R., \& Meece, J. L. 2008. Motivation in Education: Theory, Research, and Application, Upper Saddle River: Pearson Education, Inc.

Smaldino, S. E., Russell, J. D., Heinich, R. \& Molenda, M. 2005. Instructional Technology and Media for Learning ( ${ }^{\text {th }}$ Ed.). Upper Saddle River: Pearson Edu-cation, Inc.

Shroff, R. \& Deneen, C. 2011.Assessing Online Textual Feedback to Support Student Intrinsic Motivation Using a Collaborative Text-based Dialogue System: A Qualitative Study.International Journal on ELearning, 10(1): 87-104.

Treagust, D. F., Chandrasegaran, A. L., Crowley, J., Yung, B. H. W., Cheong, I. P. A.\& Othman, J. 2010. Evaluating Students' Understanding of Kinetic Particle Theory Concepts Relating to the States of Matter, Changes of State and Diffusion: A CrossNational Study. International Journal of Science and Mathematics Education,8(1): 141-164.

Vaughan, N. 2007.Perspectives on Blended Learning in Higher Education.International Journal on E-Learning, 6(1): 81-94.

Watson, J. 2008. Blending Learning: The Convergence of Online and Face-to-Face Education.North American Council for Online Learning (NACOL), (Online), (http://files. eric.ed.gov/fulltext/ED509636.pdf, diakses 20 Agustus 2015).

Wijaya, I K.W.B, Kirna, I M. \& Suardana, I N. 2012.Model Demonstrasi Interaktif dan Hasil Belajar IPA Aspek Kimia Siswa SMP Kelas VII. Jurnal Pendidikan dan Pengajaran, 45(1): 2301-782. 